\title{
El rito de purificación sinto-budista, en dos cuentos de Últimos fuegos de Alejandra Costamagna.
}

\section{The rite of Shinto-Buddhist purification, in two short stories of Últimos fuegos of Alejandra Costamagna.}

Esta obra está bajo una Licencia Creative Commons Atribución 4.0 Internacional. DOI: $\underline{10.32870 / \text { sincronia.axxiii.n75.12a19 }}$

\section{Cho, Yeonhee}

Universidad Nacional de Seúl

cyhee0110@snu.ac.kr

(COREA DEL SUR)

Recibido: $29 / 10 / 2018$

Revisado: $22 / 11 / 2018$

Aprobado: 05/12/2018

\section{RESUMEN}

Este artículo ofrece una interpretación sinto-budista de dos cuentos de Alejandra Costamagna. Mediante el análisis de "La epidemia de Traiguén" y "El último incendio" de Últimos fuegos, se revisan sus puntos comunes y diferencias como dos procesos distintos de la epidemia referida en el primer cuento de la serie. Con base en la única palabra japonesa incluida en el libro, la cual remite a un ritual de purificación sinto-budista, se pueden interpretar los cuentos, uno de los cuales tiene a Japón como espacio principal de la trama. Mientras que en "La epidemia de Traiguén", dicha epidemia generada por las situaciones inestables provoca la muerte de la protagonista, la epidemia que se traslada como contagio al cuento "El último incendio" se purifica por medio del incendio, que es una de las maneras de purificar en los ritos sinto-budistas.

Palabras clave: Epidemia. Purificación. Sinto-budismo. Literatura chilena. 


\begin{abstract}
This article offers a Shinto-Buddhist interpretation of two short stories of Alejandra Costamagna. Through the analysis of "La epidemia de Traiguén" and "El último incendio" of Últimos fuegos, one can read the common points and different points as two distinct processes of the epidemic mentioned in the first short story of the series. It is possible to interpret the stories based on the sole Japanese word included in the book, which reminds of the rite of Shinto-Buddhist purification, and on the narrative space, Japan. While in "La epidemia de Traiguén", the mentioned epidemic created by the unstable situations provokes the death of the heroine, the epidemic moved to the second short story "El último incendio" as infection becomes purified by means of the fire, which is one of the ways of purification in the Shinto-Buddhist rites.
\end{abstract}

Keywords: Epidemic. Purification. Shinto-Buddhism, Chilean Literature.

\title{
1. Introducción
}

Últimos fuegos (2005) de la autora chilena Alejandra Costamagna es un buen ejemplo que muestra cómo una colección de cuentos se unifica bajo un motivo que aparece en su título, 'fuego' en este caso, con la función de relacionar los distintos relatos. En este libro hay dieciséis cuentos. A lo largo del libro, hay ciertos elementos que se repiten y, entre ellos, el más destacado es el fuego. La intratextualidad es evidente. Por ejemplo, un personaje que aparece en un cuento reaparece en otro, y un acontecimiento ya tratado se menciona en otro relato. Por ello, los relatos integran una especie de rompecabezas y, según la autora, es una especie de caleidoscopio donde hay un juego de perspectivas (Jara, 2005).

Entre los cuentos de este libro, destacan dos: "La epidemia de Traiguén" y "El último incendio". Ambos constituyen el inicio y el fin de la segunda mitad del volumen y, en cuanto al orden en que aparecen en el índice, corresponden al noveno y al decimosexto. Sus historias son 
semejantes: una relación triangular entre una pareja y un personaje más. En los dos relatos existe un desplazamiento desde un lugar a otro casi desconocido para los protagonistas. El segundo cuento, "El último incendio", tiene un matiz de conclusión por la palabra "último", por lo cual podríamos deducir que habría una relación entre ambos cuentos seleccionados como corpus para este estudio, los cuales empiezan y terminan la segunda mitad del libro.

Para analizar las relaciones existentes, convendría preguntarse por qué la autora eligió esos títulos, por qué se repite el incendio en los relatos y qué significa. En busca de una lectura que les dé respuesta, en este trabajo propondremos tres hipótesis: 1) los dos cuentos tienen una trama y estructuras semejantes y habría un sentido oculto entre los dos cuentos; 2) los dos cuentos tratan del mismo tema que sería el de la epidemia, y 3) habría un ciclo que empieza con la epidemia y que termina con el incendio, el cual significaría un rito de purificación. Para comprobarlas, compararemos los dos cuentos en el desarrollo de sus tramas. Después, revisaremos la diferencia de los desenlaces. El análisis de las diferencias y de sus sentidos estará iluminado desde el enfoque del espacio común: Japón. Por último, veremos cómo se puede interpretar la relación entre los dos cuentos y qué significa el incendio.

\section{2. "La epidemia de Traiguén" y "El último incendio": semejanzas y diferencias}

En "La epidemia de Traiguén" hay dos personajes principales, Victoria y Santiago. Victoria es una muchacha "muy pero muy loca" (Costamagna, 2005, p. 67). ${ }^{1}$ Se enamora de Santiago, su jefe y gerente de Pollos Traiguén Ltda., y cuando Santiago la abandona para mudarse a Kamakura, Japón, nuestra protagonista lo sigue hasta ese país desconocido para ella. Consigue trabajo cuidando al bebé de una argentina y un día, inesperadamente, ve a su exjefe entrar a un hotel con una geisha. El bebé que se había quedado en el coche con la calefacción al máximo muere y, al entrar a la habitación de Santiago, Victoria también muere atacada por la japonesa con un cuchillo.

\footnotetext{
${ }^{1}$ Citaremos ambos cuentos por esta edición, con las iniciales (ET) para "La epidemia de Traiguén", y para el cuento "El último incendio" utilizaremos (UI).
} 
En "El último incendio", también tenemos a un hombre, Canossa, que se enamora de Amanda. Cuando la pareja se muda a Retiro, pueblo de Amanda, interrumpe la relación de la pareja el tío de la joven, Juan. Después de abrir un bar en Retiro, Canossa se siente engañado por su mujer. Amanda acude adonde vive su tío y, un día, regresa en la madrugada abrazada por Juan que la toma por la cintura. Canossa lo ve todo. A la mañana siguiente, el cuarto donde duerme Amanda se descubre quemado y Amanda se halla muerta por el incendio.

No es difícil encontrar algunos puntos comunes entre los dos relatos. Son historias de relaciones triangulares donde hay personajes abandonados, Victoria y Canossa. Sin embargo, la semejanza es más que un mero love affair. En cuanto a la estructura espacial, se puede advertir el mismo movimiento en las narraciones. "La epidemia de Traiguén" empieza su relato en Japón: “Se llama Victoria Melis y ha llegado a Japón" (p. 67). Pero, dice el texto: “El episodio de Victoria y Bueno comienza antes. Cinco o seis meses antes" (p. 68). Dicho episodio tiene lugar en Santiago de Chile. Hay una brecha de cinco o seis meses entre el inicio y el desplazamiento a Japón: “Victoria Melis está ahora con su maleta café en la calle Yuigahama, en Kamakura" (pp. 72-73). En “El último incendio", el cambio espacial es similar. El primer lugar que aparece en la historia es Retiro: "Canossa viajará a Retiro desde la capital" (p. 135). Pero el inicio temporal es una "noche parcialmente nublada en la capital" (p. 135). Después de su primer encuentro con Amanda, "[a] los seis meses, Amanda y Canossa se trasladan a Retiro" (p. 141). Igual que "La epidemia de Traiguén", el primer espacio que aparece en la historia es el lugar adonde la pareja va a mudarse. Entre el inicio de la historia y el desplazamiento, hay seis meses. Este cambio de lugar es la primera semejanza que puede observarse.

Entre los dos relatos, hay otros puntos en común; el más significativo es la historia familiar de los protagonistas. Victoria obtiene "[I]a herencia de sus padres, muertos en un accidente ferroviario" (p. 68), y en la historia familiar de Canossa se menciona "la muerte de sus padres en un accidente ferroviario" (p. 137), también. Así que se podría considerar a los dos protagonistas como semejantes. Comparten el rasgo de enamorarse rápido y el hecho de que han sido abandonados por 
sus parejas. Al verse abandonados en la relación triangular, Victoria y Canossa se configuran como personajes inestables en su carácter. Además, los lugares a los que se mudan para seguir o acompañar a sus novios son desconocidos tanto para Victoria como para Canossa. Victoria no tiene ningún conocimiento de la lengua japonesa y Canossa miente al decir que conoce Retiro de nombre, lo que significa que es un lugar desconocido para él. En los dos cuentos, se usan términos con sentido de sorpresa, como "inesperado" y "de golpe". También, puede observarse una comunicación imperfecta entre los novios. Los numerosos rasgos que comparten los dos cuentos se pueden resumir en uno: la inestabilidad. Por esos puntos comunes, es posible vincular y comparar los dos relatos, además de que se puede presumir un sentido oculto entre ambos que trataremos de revelar a través del análisis de las diferencias.

No obstante, sus semejanzas, los desenlaces son contrarios. En “La epidemia de Traiguén”, la que muere es la abandonada, Victoria: "La muchacha se desploma como un pato recién cazado. Como un pollo afectado por la epidemia de Traiguén" (p. 79). Pero en "El último incendio", Amanda, el personaje que abandona a su novio, es la que muere por el incendio: "Esa madrugada se declara el incendio en la veintiocho. Cuando llegan los bomberos, Amanda ya está muerta" (p. 168). ¿Por qué las víctimas son las mujeres? Estos textos muestran a las mujeres como víctimas en las relaciones inestables.

Sin embargo, los personajes femeninos no son iguales. Como hemos revisado, los personajes semejantes son Victoria y Canossa, aunque Victoria muere, pero Canossa, también abandonado, permanece con vida. Sería mejor proponer que los dos relatos tienen una gran diferencia en sus desenlaces. Y dicha diferencia se podría considerar como distintos resultados de la 'epidemia'. Como en el título, la epidemia empieza en "La epidemia de Traiguén” y contagia el texto “El último incendio" por su semejanza. El primer relato nos muestra el síntoma de la epidemia y el resultado del fracaso en curarla. La epidemia contagiosa termina en el segundo cuento por el incendio, lo cual confirma la hipótesis de este trabajo. Nuestra propuesta es que los dos relatos comparten el mismo tema, la epidemia, y que la epidemia termina con el incendio que funciona como un rito de 
purificación. En el siguiente apartado, comprobaremos esta hipótesis desde un punto de vista de la cultura japonesa.

\section{El punto de vista sinto-budista}

Uno de los elementos más llamativos en los cuentos es la inclusión de caracteres japoneses: 自動車お禑所 (p. 73). Es la única palabra en japonés en todo el libro. Hay otras frases japonesas, pero están escritas en alfabeto latino. Suponemos que habría alguna razón para mantener esta palabra en kana, ya que a través de ella se destaca el acto de purificar. En la siguiente frase se da la traducción de la palabra misteriosa en japonés: "«Aquí se ofrece el servicio de purificar vehículos nuevos»" (p. 73, las comillas son del texto). ¿A qué se referiría exactamente la purificación u oharai? Oharai significa purificar lo manchado o lo maldito (kegare). El análisis de "La epidemia de Traiguén" y "El último incendio" con base en este concepto ajeno a la cultura occidental se justifica por el espacio elegido en el primer relato: Japón.

En las obras de Alejandra Costamagna, Japón aparece varias veces. En una entrevista, Costamagna explica el porqué incluye Japón en sus obras:

[H]ay algo que me atrae mucho de Japón, de su estética, cineastas, ilustradores. Pero en este caso, es más bien una figura metafórica que marca una especie de contraste en cuanto nuestras experiencias muy subjetivas y probablemente un poco manipuladas desde el occidental en visión del oriental. (Cheregue y Uribe, 2016)

Como afirma la escritora, Japón, un país tan lejano de Chile, es un espacio donde dominarían otros conceptos. Si la autora sitúa un cuento en Japón, sería justificable analizarlo cuento desde un punto de vista distinto, que podría ser la manera de ver el mundo en Japón. Por lo tanto, nos concentraremos en Kamakura, lugar donde ocurre "La epidemia de Traiguén".

Kamakura es una ciudad conocida por su templo sintoísta, Tsurugaoka-Hachimangu y por la estatua enorme de Buda. Se puede decir que Kamakura es el lugar sinto-budista por excelencia. Así 
como Victoria ve el cartel anunciando“自動車お祓所”(p. 73), en Kamakura, cerca del templo Tsurugaoka-Hachimangu, los visitantes pueden encontrar carteles con la misma palabra. El oharai es la creencia en que puede borrarse lo manchado, llamado kegare, a través de un rito de purificación mediante oraciones y ciertos actos simbólicos.

Según Kenji Nakamura (2007, p. 75), la oración para el automóvil es uno de los ritos más frecuentes que se realizan en los templos budistas, con el desarrollo de la industria automotriz. Y como Japón es un país con cultura sinto-budista, la oración del automóvil se lleva a cabo también en los templos sintoístas (Kazuhiko, 2006, pp. 4-7).

La palabra japonesa “自動車お秡所”y el espacio de Kamakura permiten interpretar los dos relatos desde una perspectiva sinto-budista. Pero ¿cuál sería el objeto a purificar en estos relatos? Hemos dicho que oharai es un acto de purificar lo machado, kegare. Si hay algún elemento equivalente al kegare en los cuentos, sería justificado deducir el incendio como un rito de purificación, oharai. Según Nobuhiro Ito, el concepto de kegare, un objeto que necesita eliminarse, tiene su origen en la influencia taoísta (yin y yang) y budista (Ito, 2002, p. 5). Kegare, lo manchado que debe purificarse, es una situación donde se pierde la estabilidad de la naturaleza y de la sociedad. A través de la purificación, se puede volver a un estado de equilibrio de nuevo (Ito, 2002, p. 7).

En "La epidemia de Traiguén" y en "El último incendio", hay referencias que remiten a lo inestable. Por ejemplo, los desplazamientos, los personajes que se enamoran tan rápidamente, el uso de vocablos como 'de golpe' e 'inesperado', y las relaciones triangulares e inestables. También, aparecen ciertas imágenes inestables, como "la muñeca de porcelana que ha caído al suelo" (p. 73) y "las cartas caen en ese preciso instante sobre la mesa" (p. 167). La relación entre Amanda y Juan es un hecho que desestabiliza la sociedad por tratarse de un incesto, sobrina-tío. Sin embargo, estos elementos son relativamente kegares leves. El gran kegare en estos cuentos sería la epidemia.

La epidemia que se menciona literalmente en "La epidemia Traiguén" sería una metáfora del kegare. En la cultura sinto-budista, la epidemia y la muerte inesperada se consideran como kegare. 
Nobuhiro Ito señala que, al igual que como se comprendía en China, en la era de Kofun que comprende en Japón del año 250 al 538, independientemente de la muerte natural, la muerte inesperada estaba considerada como destructora del equilibrio natural y social, de manera que la función que se añadió al oharai fue la de purificar ese kegare (Ito, 2002, p. 11). Con esta información, podríamos interpretar la epidemia como un kegare. Normalmente, los pollos de Traiguén estaban bajo un control naturalmente óptimo: "Pollos de exportación, que no son alimentados con pescado ni inflados con hormonas y que tienen una muerte no digamos dulce pero en ningún caso estresante" (p. 67). De repente, los pollos contraen la epidemia y "[c]uando los pollos son contagiados se debilitan, enflaquecen, se ponen muy feos. Es como si de golpe se vieran afectados por una depresión crónica. Ése es el único síntoma. Y un día cualquiera caen muertos" (p. 67). La epidemia que afecta el estado natural de los pollos significa la inestabilidad, el kegare, según señala el cuento refiriéndose al negocio de Pollos Traiguén Ltda.

\section{Los personajes contagiados por la epidemia}

La epidemia se extiende y contagia a los personajes de los cuentos. El síntoma más destacado es la depresión. Este síntoma se observa en los protagonistas. En el caso de Victoria, no es tan grave como Canossa. Cuando Victoria llega a Kamakura y trabaja para la argentina, Victoria muestra dicho síntoma levemente: "Elsa Aránguiz comienza a notar rara a la muchacha. Te veo decaída, le dice, como medio apagada" (p. 75). Victoria misma se percibe que está en un mal estado psicológico: “Me voy a volver loca, loca" (p. 76). Pero este síntoma no se cura, sino que la hace morir por la obsesión de seguir al exnovio al tiempo que provoca también la muerte de un inocente.

En "El último incendio", el síntoma de la depresión o la epidemia se presenta con más fuerza en Canossa. Este personaje ya sufría algún tipo de depresión y tomaba medicamentos para tranquilizarse. Se podría decir que a Canossa ya le afectaba la epidemia. Pero suspende la medicina al mudarse a Retiro con Amanda. Antes de salir, Amanda le dice a Canossa sobre el nuevo espacio: “Además, yo te puedo enseñar las mañas de Retiro. Porque es un lugar mañoso, tienes que saberlo" 
(p. 140). Desplazarse a Retiro significa ir a un lugar en donde no se puede confiar en nadie, donde no hay nada estable porque todo podría desplomarse por "las mañas". Hasta Amanda es un personaje 'mañoso'. Al percibir que su mujer lo está engañando, el estado mental de Canossa cae en una depresión más grave. Cuando Juan va a visitar a Amanda, la escena de Canossa no se describe junto a su novia, sino que en el texto aparece una imagen de este personaje junto a un pollo, con lo cual el lector podría recordar la epidemia de los pollos del cuento con ese título. Y en ese marco, se agrava la epidemia o la enfermedad mental de Canossa. El síntoma de depresión empieza con un pánico que desdobla la conciencia del personaje:

Está muy lejos de pensar en el fuego. Pero la calma aparente no impide que en una de las secuencias de oscuridad vea su propia sombra agigantada y sienta pánico. Es un pánico extraño, algo físico: él no habita su cuerpo; es decir, lo habita, pero sobra en él. Puede escuchar su respiración, pensar sus pensamientos, observarse desde afuera. (p. 151)

El síntoma de sentirse fuera de su propio cuerpo es signo de despersonalización: "a subjective experience of unreality and detachment from self, [...] [t]ransient depersonalisation would appear to be common, and has been found to be the third most frequently reported psychiatric symptom after anxiety and depression" (Lambert, 2001, pp. 249-250). Como "Canossa se mira las manos, las piernas, el cuerpo entero, y tiene la sensación de no estar ahí" (p. 158), muestra uno de los síntomas de la depresión. Pero cuando encuentra un orden y una estabilidad, se tranquiliza: “Después pasa un paño húmedo por el mostrador y por un instante tiene la sensación de que el orden y la limpieza de las cosas materiales le provocan un alivio insuperable. Un alivio como un estornudo" (p. 158).

Sin embargo, dicha estabilidad que lo hace sentir tranquilo dura poco y la inseguridad de su relación reactiva la epidemia con otro síntoma de depresión, el insomnio: "A partir de esa madrugada Canossa comienza a perder el sueño" (p. 159). Según el listado de signos de la depresión (Beck, Ward, Mendelson \& Mock, 1961, pp. 561-571), no poder dormir es un síntoma de depresión junto con sentirse irritado fácilmente, lo mismo que siente Canossa: "Canossa se siente agredido 
por ese gesto" (p. 162). Su sentir "como si detrás del rumor de la muchedumbre se escondiera un secreto que solo él desconoce" (p. 163), también se relaciona con el sentimiento de culpabilidad, otro síntoma de depresión. El sufrimiento de Canossa con los síntomas evidentes de la depresión significaría el contagio efectivo de la epidemia. Pero en las últimas páginas, la culpable que produjo la inestabilidad de Canossa, Amanda, muere por el incendio que ocurre donde ella duerme. La eliminación del elemento inestabilizador significaría eliminar el kegare. Y eliminar el kegare con el fuego puede querer decir un acto de purificación.

\section{Conclusión}

Hemos visto dos tipos de kegares representados por la epidemia. Prevalece una epidemia, cuyo síntoma es la depresión de los protagonistas en los dos relatos, aunque el resultado de cada texto sea diferente. Con base en esta diferencia, indagamos qué significaría el incendio o el fuego en los relatos. El discurso no ofrece ningún criterio para interpretar el sentido del fuego, sino que da varias opciones para interpretarlo. Alejandra Costamagna dice en una entrevista: "No pretendo hacer una teoría sobre el fuego y los cuentos" (Jara, 2005). Ante esta declaración, se puede proponer una interpretación desde un punto de vista sinto-budista, que está sugerido por el espacio del primer texto.

Sobre el simbolismo del fuego, según el Diccionario de símbolos de Cirlot (1992, p. 208), “las investigaciones antropológicas han dado dos explicaciones de los festivales ígnicos: magia imitativa destinada a asegurar la provisión de luz y calor en el sol, o finalidad purificatoria, y destrucción de las fuerzas del mal". El simbolismo del fuego con un sentido mágico que tiene un papel purificador y destructor también existe en Asia, especialmente desde la perspectiva budista. El fuego tiene capacidad de controlar el poder natural, como las tempestades, y un poder mágico que lleva el buen principio celeste a los humanos (Laboratorio del Budismo, 2002, p. 28). El fuego como un poder mágico puede purificar. Junto con el agua, el fuego tiene un simbolismo de función 
purificadora (Laboratorio del Budismo, 2002, p. 40). Por eso, podemos relacionar el fuego en el texto con el simbolismo del fuego purificador.

Pero el fuego con una función purificadora solo aparece en el segundo relato, "El último incendio". Como indica su título, el incendio es esencial para interpretar ese texto. Nuestra última hipótesis es que la epidemia empieza en "La epidemia de Traiguén" y termina con el incendio en "El último incendio", un ciclo como un rito de purificación ya que, como hemos señalado, la epidemia aparece en ambos relatos. Hemos analizado que el inicio de la epidemia del primer relato se extiende y contagia a los personajes del segundo texto. El escenario donde muere Victoria ofrece la imagen de un pollo que cae muerto por la epidemia: "La muchacha se desploma como un pato recién cazado. Como un pollo afectado por la epidemia de Traiguén" (p. 79). Se podría leer que la epidemia empezada en el inicio del texto no termina, sino que deja una víctima.

En "El último incendio", tenemos un personaje que ya sufre depresión contagiado por la epidemia. Con el paso del tiempo, la inestabilidad generada por Amanda y la relación triangular se agudiza y la epidemia que padece Canossa empeora. Podríamos interpretar que dicho empeoramiento de la epidemia es resultado de que no se ha extinguido la epidemia en el relato donde se inició. La epidemia termina con un incendio, que sería un fuego purificador. Hemos revisado que es posible interpretar los dos cuentos como enlazados para analizarlos desde un punto de vista sinto-budista, debido a la inclusión de palabra “自動車お戨所”y del espacio japonés.

Sin embargo, queda una duda. En las últimas páginas, hay ambigüedad: no sabemos exactamente como inició el incendio en el cuarto de Amanda. La narración confunde el sentido con dos frases que cambian de tercera a primera persona, "la mira por última vez" (p. 168), una frase antes del incendio, y "entonces la miré y ya no me parecía nada, dirá. Y luego: El fuego la había deformado. Yo la vi quemarse" (p. 169). No sabemos si Canossa miró a Amanda o no cuando ella estaba en el fuego. Esta ambigüedad nos llevaría a una nueva pregunta: ¿se acabó la epidemia? Como todavía queda cierta ambigüedad, los lectores estarían entrando en un estado de 
inestabilidad igualmente que el protagonista. Quedar contagiados por la lectura sería otra posibilidad de interpretar estos dos cuentos de Últimos fuegos.

\section{Referencias}

Beck, A.T., C. H. Ward, M. Mendelson \& Mock, J. (1961). An Inventory for Measuring Depression. Archives of General Psychiatry, 4, 561-571.

Cheregue, M. y S. Uribe (2016). Entrevista: «Me gusta trabajar con los intersticios, lo que corre bajo la superficie». Punto y Coma. Obtenido el 23 de mayo de 2017 de http://www.puntoycoma.pe/bohemia/entrevista-gusta-trabajar-con-los-intersticios-loque-corre-bajo-la-superficie/.

Cirlot, J. E. (1992). Diccionario de símbolos. 9a. ed. Barcelona: Labor.

Costamagna, A. (2005). Últimos fuegos. Santiago: Ediciones B.

Ito, N. (2002). Reflexión sobre el kegare y los límites: kegare y ke. Studies in Language and Culture, 24, 3-22.

Jara, X. (2005). Alejandra Costamagna: Mis personajes son hijos del insomnio. El Mostrador. Obtenido el 23 de mayo de 2017 de http://www.elmostrador.cl/cultura/2005/09/13/alejandra-costamagna-mis-personajesson-hijos-del-insomnio/?php\%20bloginfo(\%27url\%27);\%20?\%3E/cultura.

Kazuhiko, Y. (2006). ¿Cómo se entiende el sinto-budismo japonés, desde el punto de vista de los estudios históricos? Revista Anual del Laboratorio de Cultura Humana, 3, 4-7.

Laboratorio del Budismo. (2002). El simbolismo del fuego y del agua. Revista contemporánea de Budismo, 15, 23-40.

Lambert, M. V. (2001). Primary and Secondary Depersonalisation Disorder: A Psychometric Study. Journal of Affective Disorders, 63, 249 -256.

Nakamura, K. (2007). The Origins and Development of Blessings for Automobiles. Journal of Research Society of Buddhism and Cultural Heritage, 7, 74-86. 